\title{
Nuevas localidades para la flora amenazada en Jaizkibel
}

\author{
Flora mehatxatuaren kokagune gehiago Jaizkibelen \\ New places for endangered plants in Jaizkibel mountain
}

\author{
Iñaki Pikabea*, Garbiñe Albisu*, Iñaki Aizpuru' \\ ${ }^{1}$ Sociedad de Ciencias Aranzadi-Aranzadi Zientzia Elkartea, Zorroagagaina 11, 20014 Donostia-S. Sebastián. \\ * Correspondencia: labetxu@hotmail.com.
}

\section{RESUMEN}

Damos cuenta del descubrimiento de nuevas localidades para 3 especies de plantas catalogadas como vulnerables en el catálogo vasco de especies amenazadas, fruto de las prospecciones realizadas durante estos últimos años en la parte occidental del monte Jaizkibel.

PALABRAS CLAVE: Plantas amenazadas, biogeografía, Comunidad Autónoma Vasca, Hymenophyllum tunbrigense (L.) Sm, Vandenboschia speciosa (Willd.) G. Kunkel, Xiphion latifolium Mill.

\section{LABURPENA}

Espezie mehatxatuen Euskadiko zerrendan zaurgarri arrisku-mailan izendatuta dauden 3 landare espezieen kokagune berriak jakitera ematen ditugu, azken urte hauetan Jaizkibel mendiaren itsas-isuriko mendebaldean eginiko azterketen aurkitutakoak, hain zuzen ere.

GAKO-HITZAK: Landare mehatxatuak, biogeografia, Euskal Autonomi Elkargoa, Hymenophyllum tunbrigense (L.) Sm, Vandenboschia speciosa (Willd.) G. Kunkel, Xiphion latifolium Mill.

\section{ABSTRACT}

We expose some unknowns localities for 3 plants species, ranged as threatened in the basque country list for endangered species. They have been found on several prospections carried in recent years among the west slopes of Jaizkibel mountain (Basque Country).

KEY WORDS: Threatened plants, biogeography, Basque Country, Hymenophyllum tunbrigense (L.) Sm, Vandenboschia speciosa (Willd.) G. Kunkel, Xiphion latifolium Mill.

\section{INTRODUCCIÓN}

Las características geológicas, topográficas y climáticas del monte Jaizkibel hacen que, en este promontorio costero de apenas $12 \mathrm{~km}$ de largo, encuentren refugio numerosas especies de plantas de distinto significado biogeográfico. Se conocen nada menos que 14 especies de plantas vasculares del catálogo vasco de especies amenazadas, entre ellas 2 en peligro de extinción y 8 vulnerables (Gobierno Vasco, 2011). A estas especies vulnerables se les ha añadido recientemente una especie de briófito, la hepática Telaranea europaea J.J. Engel \& G.L. Merr (Gobierno Vasco, 2013), endémica europea de distribución estenoatlántica que, en el País Vasco, sólo se conoce de Jaizkibel.

Pero el número y distribución de las poblaciones de plantas amenazadas en Jaizkibel distan aun de ser bien conocidos y el renovado interés por esta montaña ha dado como fruto el hallazgo de nuevas poblaciones de tres de estas especies, mejorando así de forma notable la el conocimiento para su efectiva protección.

\section{MATERIAL Y MÉTODOS}

Las poblaciones aquí señaladas se han localizado en repetidas visitas realizadas estos últimos años a las laderas que dan al mar en el extremo occidental de Jaizkibel y, más concretamente, en el término municipal de Pasaia.
Se han recorrido sistemáticamente las laderas y barrancos que, en esta parte occidental, tienen algunos cursos de agua permanente de escasa entidad aunque, en su mayor parte, los cursos son intermitentes o inexistentes en superficie.

\section{RESULTADOS}

\section{Hymenophyllum tunbrigense (L.) Sm}

SS: Pasaia, monte Jaizkibel, Gaztarrotz, 30TWP9101, 85-90 m, paredes silíceas cubiertas de musgos, observaciones entre 2004 y 2010, s.t.

Helecho paleotropical, distribuido por las islas de la Macaronesia y la cornisa cantábrica., que cuenta con un número muy reducido de poblaciones en la Comunidad Autónoma, casi todas en la parte oriental de Gipuzkoa más una población aislada en el monte Sollube de Bizkaia, que son consideradas en conjunto como 'vulnerables' en el Catálogo Vasco (Gobierno Vasco, 2011).

Los primeros en citar este helecho de Jaizkibel fueron los Allorge (P. et V., 1941: 229), que hablan de un barranco marítimo. Desde entonces, las poblaciones conocidas para este helecho en Jaizkibel se reducían a dos (Catalán \& Aizpuru, 1984: 255), ambas en el término municipal de Hondarribia. Esta nueva localidad amplía su distribución al término municipal de Pasaia (Fig. 1). 
Las nuevas poblaciones de $H$. tunbrigense descubiertas viven en paredes verdes y musgosas de varios metros de altura de las rocas silíceas del lugar denominado Gaztarrotz, cerca de las ruinas del caserío de igual nombre. A lo largo del roquedo, que baja hasta el arroyo, existen unos pasos naturales que siempre han sido usados tanto por humanos como por el ganado para llegar a su parte alta. Es en estos pasos donde encontramos el helecho $H$. tunbrigense. Se trata de paredes húmedas y sombrías con mucha vegetación. El helecho ha sido localizado en dos de esos pasos naturales: en la pared izquierda de uno de ellos pueden observarse 5 núcleos distintos, a una altura de $90 \mathrm{~m}$, dispersos entre el musgo. Otra población aparece en otro paso del roquedo, a 85 m, también en la pared izquierda.

\section{Vandenboschia speciosa (Willd.) G. Kunkel (Trichomanes speciosum Wild.)}

SS: Pasaia, monte Jaizkibel, Ertxinarri, 30TWN8999, 90 y $96 \mathrm{~m}$, oquedades del acantilado que da al mar, observación en 2012, s.t.

SS: Pasaia, monte Jaizkibel, Auzleia, 30TWN 8898, $135 \mathrm{~m}$, varias manchas en bosquete de madroños y laureles, observación en 2013, s.t.
Es otro helecho de distribución subtropical, que se extiende hasta la Macaronesia y el occidente europeo, sobre todo en la Península Ibérica, donde se limita a la cornisa cantábrica y las montañas de Algeciras. En la Comunidad Autónoma está repartido por buena parte de la vertiente atlántica, aunque siempre en poblaciones pequeñas y fragmentadas, razón por la que está considerada como 'vulnerable' en el Catálogo Vasco de Especies Amenazadas (Gobierno Vasco, 2011).

Gandoger (1898: 29) fue el primero en dar cuenta de su presencia en Jaizkibel y en todo el País Vasco. Además, dice haberla encontrado en Pasajes (también por encima de Hondarribia), por lo que vería estas mismas poblaciones u otras próximas, más de cien años atrás. Desde entonces se había verificado su presencia en la parte de Hondarribia (Catalán \& Aizpuru, 1984: 255; Aseginolaza \& al., 1985: 27) pero no hasta ahora en Pasaia, donde también se ha encontrado recientemente otra población (SanzAzkue et al., 2014).

Hemos descubierto dos nuevas localidades en el término municipal de Pasaia, la primera en la zona conocida como Ertxinarri, con dos manchas a 90 y $96 \mathrm{~m}$ de altitud respectivamente, en Abr. de 2012. Estas dos manchas, a diferencia de los ya localizados en Hondarribia que aprovechan las cercanías de riachuelos y el abrigo de barran-

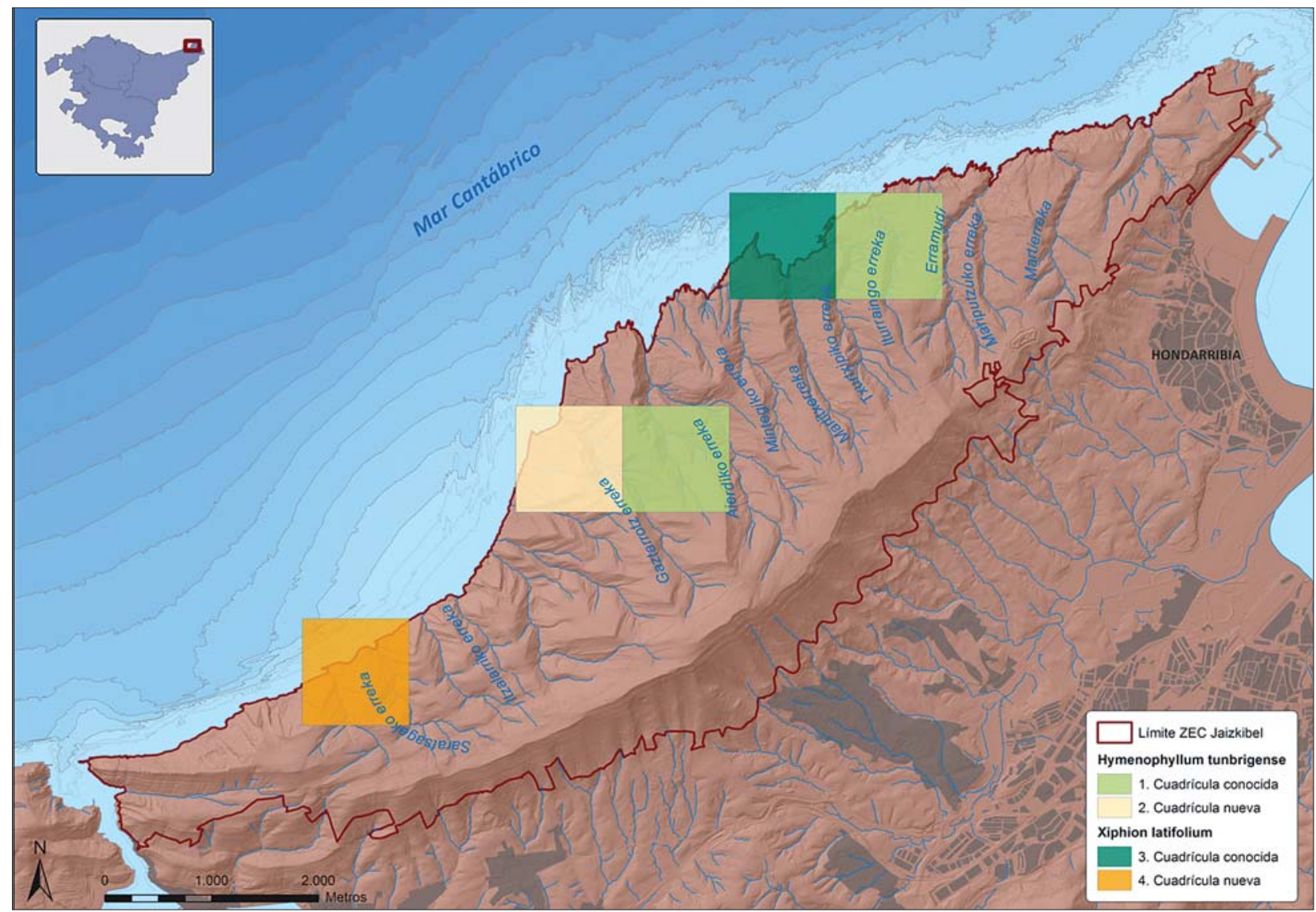

Fig. 1. - Distribución de H. tunbrigense y X. latifolium en Jaizkibel.

1. Irudia. Jaizkibelen $H$. tunbrigense y $X$. latifolium kokapena. 
cos y bosques, sobreviven en pequeñas oquedades del acantilado marino, muy expuestas a las inclemencias meteorológicas. El lugar es de difícil acceso, dada la inclinación del acantilado. La primera de las manchas, con ejemplares muy jóvenes, se encuentra en la pared de una roca cubierta de musgo, bajo una higuera que la protege. La segunda, con ejemplares más grandes, habita en una pequeña oquedad sombría y húmeda. Las dos poblaciones consiguen sobrevivir con la humedad que baja por el acantilado, ya que no tienen cerca ningún riachuelo.

La segunda de las localidades cuenta con varias manchas que se extienden a lo largo de $10 \mathrm{~m}$ en un pequeño bosque de madroños y laureles, también de muy dificil acceso, a una altitud de $135 \mathrm{~m}$, en el lugar llamado Auzleia cerca de Porrustarri. Al igual que en el caso anterior, no están asociadas a arroyos permanentes. Ambas localidades se han reflejado en el mapa que da cuenta de la distribución conocida de este helecho en Jaizkibel, en esta misma publicación (Sanz-Azkue et al., 2014).

\section{Xiphion latifolium Mill. (Iris latifolia (Mill.) Voss)}

SS: Pasaia, monte Jaizkibel, Sanjuanarri, 30TWN8999, 85 y 175 m, landa-helechal en vaguada y en ladera hacia el mar, 2004 y 2010, s.t.

Especie típica de los pastos de alta montaña, endémica del Pirineo y la Cordillera Cantábrica, que, aunque es más abundante en los pastos montanos y subalpinos (entre 1.000 y más de 2.400 m de altitud) cuenta con algunas poblaciones costeras en el extremo occidental de Bizkaia y el oriental de Gipuzkoa. Algo semejante ocurre con Lilium pyrenaicum Gouan, que abunda en los acantilados costeros, o con Saxifraga clusii Gouan en la cercana Aiako Harria. En conjunto, evocan tiempos pasados, en el que estas especies, adaptadas a climas más fríos que el actual, debían tener una distribución continua, desde el litoral hasta las elevaciones montañosas.

Por su rareza en la Comunidad Autónoma Vasca, está protegida con la categoría de 'vulnerable'. En Jaizkibel tan sólo se conocía una población, en la vecina Hondarribia (Catalán \& Aizpuru, 1985: 71), a la que se suman estas dos nuevas poblaciones halladas en el extremo occidental de Jaizkibel, en su cara norte, zona conocida como Sanjuanarri (Fig. 1). En la primera, localizada en 2004 a una altura de $85 \mathrm{~m}$ en una pequeña vaguada, se pudieron contar unos 200 ejemplares en 2012, en su mayor parte en flor. La segunda, localizada en 2010 a una altura de 175 m, en la ladera opuesta a la primera, cuenta con 60 ejemplares, y parece estar en buen estado estos últimos años.

\section{BIBLIOGRAFÍA}

Allorge, V., Allorge, P. 1941. Plantes rares ou intéressantes du NW. de I'Espagne, principalement du Pays basque. Bull. Soc. bot. France 88: 226-254.

Aseginolaza C., Gomez, D., Lizaur, X., Montserrat, G., Morante, Salaberria, M.R., Uribe-Echebarría, P.M. 1985. Araba, Bizkaia eta Gipuzkoako landare katalogoa. Gobierno Vasco. Vitoria-Gasteiz.
Catalán, P., Aizpuru, I. 1984. Pteridófitos del Monte Jaizkibel (Guipúzcoa). An. Biol. Univ. Murcia 1: 253-265.

Catalán, P., Aizpuru, I. 1985. Aportación al catálogo florístico de la cuenca del Bidasoa (Guipúzcoa y Navarra). Munibe Cienc. Nat. 37: 17-86.

Gandoger, M. 1898. Notes sur la flore espagnole. Bull. Soc. Bot. Fr. 45: 17-29.

Gobierno Vasco 2011. Orden de 10 de enero de 2011, de la Consejera de Medio Ambiente, Planificación Territorial, Agricultura y Pesca, por la que se modifica el Catálogo Vasco de Especies Amenazadas de la Fauna y Flora Silvestre y Marina y se aprueba el texto único.

Gobierno Vasco 2013. Orden de 18 de junio de 2013, de la Consejera de Medio Ambiente y Política Territorial, por la que se modifica el Catálogo Vasco de Especies Amenazadas de Fauna y Flora Silvestre y Marina.

Sanz-Azkue, I., Olariaga, I., Felipe, A. 2014. Vandenboschia speciosa (Willd.) G. Kunkel en Jaizkibel: nuevas poblaciones con alta representación de su fase gametofítica y modelización de su distribución. MunibeMonographs. Nature Series 2. En prensa. 